\title{
LA RESPUESTA A LA EMERGENCIA COVID-19: EL CASO ITALIANO
}

\author{
Anna Mastromarino \\ Professoressa Associata di Diritto Pubblico Comparato \\ Università di Torino
}

Cómo citar este artículo / Citation: Mastromarino, A. (2020). La respuesta a la emergencia Covid-19: el caso italiano. Biglino Campos, P.; Durán Alba, F. Los Efectos Horizontales de la COVID sobre el sistema constitucional, Colección Obras colectivas, Fundación Manuel Giménez Abad, Zaragoza. DOI: https://doi.org/10.47919/FMGA.OC20.0024

SUMARIO: I. COVID-19: UNA PANDEMIA GLOBAL - II. EMERGENCIA Y ESTADO CONSTITUCIONAL DEMOCRATICO - III. EL ESTADO DE EMERGENCIA EN ITALIA - IV. ORDENANZAS NECESARIAS: HABLANDO DE ESTADO REGIONAL - V. MIRANDO HACIA EL FUTURO. EL VALOR DE LAS INQUIETUDES DEL JURISTA - VI. BIBLIOGRAFÍA

\section{COVID-19: UNA PANDEMIA GLOBAL}

Podemos declararlo sin rémoras: lo que hemos vivido y todavía estamos viviendo no tiene precedentes.

No es posible ir buscando términos de comparación respecto a la pandemia covid-19 que ha afectado el mundo en el año 2020. Y eso porque, a pesar de las posibles similitudes, por primera vez nos enfrentamos a una epidemia que además de mundial (porque aflige la casi totalidad de los países en el mundo), es global, o sea mediática, conectada y gestionada tecnológicamente: una pandemia vivida en directo; una pandemia que obliga a los Estados (excepto unas pocas excepciones) a confrontarse entre ellos; una pandemia que ha movilizado a la comunidad científica mundial, empujando a una colaboración sin fronteras; una pandemia en cuya reducción la ciencia y la técnica juegan un rol esencial y en cuya gestión también la opinión pública mundial ocupa un papel fundamental. 
En este sentido es fácil suponer que, día a día, la dimensión nacional haya quedado inevitablemente condicionada y, por lo tanto, directamente afectada por una dimensión supranacional, que a esta tragedia le otorga un toque casi democrático, habida cuenta de que el virus covid-19 está golpeando todos los países, independientemente de su producto interior bruto, de su nivel de desarrollo económico, de su estructura demográfica...

Cuidado: he dicho "casi democrático"; y eso porque la naturaleza democrática del contagio va desenfocándose si pasamos a analizar aspectos relacionados con las consecuencias prácticas que lleva consigo una pandemia, teniendo en cuenta que a la hora de enfrentarse en concreto con la emergencia, el nivel de riqueza, la estabilidad democrática y el bienestar social de cada país, influyen patentemente en las condiciones de vida de los ciudadanos.

$Y$ es bajo esta perspectiva que la dimensión nacional vuelve a tomar protagonismo y el rol del Estado crece a pesar de todo, sobre todo a la hora de asumir estrategias de enfrentamiento al virus, decisiones que afectan a la vida de los ciudadanos, medidas de protección de la salud pública y resoluciones por lo que concierne a la política económica de cada país.

Sin duda, Italia ha sido uno de los países más afectados por el virus en términos de fallecimientos y, entre las democracias liberales maduras, uno de los primeros países en enfrentarse con la pandemia covid-19.

Lo cual no es poco, pues en una situación extraordinaria de emergencia no tener términos de comparación puede convertirse en un considerable factor de debilidad.

Efectivamente, no cabe la menor duda de que la gestión de la emergencia dentro del marco de lo "democráticamente permitido" se convierte en una tarea mucho más pesada porque no puede prescindir de límites y controles, de balances entre los poderes, de consenso. Incluso recurriendo a medidas de urgencia, un Estado democrático constitucional tiene que preferir extender el tiempo necesario para tomar decisiones, en vez de permitir la consolidación de poderes personales. Esto porque en los Estados constitucionales democráticos, incluso en condiciones de emergencia, el objetivo no cesa de ser la salvaguardia de sus valores y la limitación de poderes, mientras los sistemas que no corresponden al modelo democrático liberal se pueden conformar con guardar su propia existencia política. 
Es indudable que la respuesta de los Estados frente a la emergencia generada por la difusión del virus ha engendrado, allá donde mires, un estado de tensión institucional; sin embargo difícilmente sería posible interpretar correctamente esta tensión sin enfrentarnos a algunos conceptos dicotómicos que nos permiten enfocar la naturaleza del contexto jurídico en el que cada sistema se ha ido moviendo.

Para ilustrar las medidas jurídicas empleadas en Italia en tiempos de Coronavirus, por lo tanto, será mejor empezar justamente por estos conceptos, propios de la teoría general del derecho, a fin de tratar posteriormente de las diferentes fuentes aplicadas.

\section{EMERGENCIA Y ESTADO CONSTITUCIONAL DEMOCRATICO}

Desde el punto de vista del sistema jurídico y político, los hechos demuestran que los Estados no estaban debidamente preparados para enfrentarse a una emergencia de esta magnitud: o no tenían una legislación adecuada para encararse a situaciones de emergencia causadas por una epidemia o, si la tenían (como en el caso de España cuya ley orgánica núm. 4/1981 incluye las crisis sanitarias entre las causas de activación del estado de alarma), su aplicación ha sido acompañada por una infinita polémica política ${ }^{1}$

\footnotetext{
1 ...sustentada por una parte de la doctrina también: en este sentido, Sánchez Ferriz, 2020, 16 ss. Por una parte se ha puesto en evidencia como solo la declaración de estado de alarma, propuesta, aprobada y prorrogada, prevé entre sus hipótesis la crisis sanitaria; por otra parte hay quien ha subrayado como durante el estado de alarma los derechos han sido más bien suspendidos que limitados y por lo tanto hubiese sido mejor activar el estado de excepción. La polémica parece apoyar la idea que "il regime adatto ad affrontare una situazione di crisi verrebbe "chiamato" dalle conseguenze piuttosto che dalla causa legittimante la sua attivazione" En realidad esta perspectiva "sembra seguire una logica "rivoluzionaria", giacché capovolge il classico paradigma decisionale, nell'affermare che si dovrebbe decidere il regime da attivare nel frangente dell'emergenza in ragione delle misure che si vogliono adottare (cioè, per quello che si vuole fare ex post) e non stando alla situazione prevista e, invero nel caso di specie, ben disciplinata ex ante. Questo schema di ragionamento non può essere condiviso almeno per due ordini di considerazioni: anzi tutto, inevitabilmente forzerebbe, in "entrata", ossia al momento dell'attivazione del regime, non solo la lettera ma anche il senso di una precisa declinazione della "costituzione dell'emergenza"; in secondo luogo, ma altrettanto importante sul piano sostanziale degli effetti, quindi in "uscita", e con specifico riferimento ai controlli, non si può fare a meno di rilevare che, in vigenza dello stato di allarme, il sistema ordinario delle garanzie giurisdizionali resta attivo e pienamente operativo, diversamente in vigenza dell'estado de excepción, allorquando le misure introdotte avessero comportato la sospensione e non la mera limitazione dei diritti, bisognerebbe prendere atto dell'inoperatività della competente autorità giurisdizionale, data l'inesigibilità del diritto sospeso" Así Vedaschi, 2020: 1463.
} 
(desembocada en recursos al Tribunal constitucional, también...) acerca de su oportunidad.

No sorprende, por lo tanto, que en las semanas sucesivas a la difusión de la epidemia, cada Estado, a partir de lo existente, haya imaginado nuevos escenarios jurídicos y normativos que han ido impactando cada vez más sobre la vida de los ciudadanos, afectando el ejercicio de sus derechos constitucionales ${ }^{2}$.

Se ha puesto en marcha, así, un intenso debate acerca de la legitimación de la actividad normativa del Estado (...efectivamente a veces muy fantasiosa), renovando la antigua disputa acerca de la emergencia como fuente de derecho y vivificando a continuación la controversia sobre la diferencia entre el estado de limitación y aquel de suspensión de los derechos.

No podemos aquí detenernos en los aspectos más teóricos que este debate plantea. Sin embargo sí merece demorarse un poco en algunas reflexiones que en primer lugar conciernen al caso italiano, pero se pueden fácilmente extender a otras experiencias.

Por precipitada y apresurada que haya sido la actividad normativa del sistema italiano, en los últimos meses $\mathrm{y}$, sobre todo, en las primeras semanas sucesivas a la declaración del estado de emergencia, hay que subrayar que en todo momento solo la Constitución, y no la necesidad en sí misma, ha sido tomada y efectivamente puede ser considerada como fundamento de la cadena normativa que se ha ido desarrollando desde finales de enero. Ni podría haber sido de forma diferente, considerando que admitir la necesidad como fuente autónoma de derecho hubiese sido realmente incompatible con la idea de supremacía de la Constitución y con su naturaleza rígida ${ }^{3}$.

Es sabido que, además de la respuesta en sí misma, es el marco jurídico en el que se realiza la respuesta a la emergencia que caracteriza el estado constitucional democrático. En este sentido, la emergencia no tiene poder de suspensión del Estado constitucional, ni representa una alternativa a las dinámicas de la democracia constitucional ${ }^{4}$. Más bien, la emergencia

\footnotetext{
${ }^{2}$ Vedaschi, 2020: 1463, habla de "huida" de los Estados respecto a las correspondientes normativas: "In estrema sintesi, le democrazie mature di tradizione liberale alla prova dell'emergenza hanno optato per la fuga dalle rispettive "discipline dell'emergenza"'“.

${ }^{3}$ Véase en este sentido Luciani, 2020: 113.

${ }^{4}$ Raví Pinto, 2020: 45, recuerda que la: "decisione intorno all'emergenza è, come si è appurato, comune allo Stato democratico e a quello non democratico; la risposta allo shock che l'emergenza impone distingue le due forme di Stato. Proprio nella graduazione delle misure e
} 
representa una casualidad que el Estado tiene que gestionar respetando la Constitución y sus límites. La emergencia por extraordinaria que sea no se pone fuera del contexto constitucional: si no se pueden prever las circunstancias, sí se pueden codificar los actos a través de los cuales las instituciones reaccionan, así tratando de "constitucionalizar" el contexto extra ordinem ${ }^{5}$.

De otra forma estaríamos abandonando el terreno de la democracia constitucional por aventurarnos en otros escenarios donde el estado de excepción puede poner en riesgo el ejercicio de los derechos constitucionales ${ }^{6}$.

Subrayar que la Constitución sigue siendo el cimiento del sistema a pesar de una condición de emergencia obliga a las instituciones a razonar en términos de ponderación de derechos y no de suspensión. Lo cual, como veremos, es muy diferente en términos prácticos y reconduce el concepto de fuente extra ordinem a su sentido constitucionalmente correcto, que supone que no se deje espacio al uso excesivo tratándose de prever una derogación del sistema que por eso tiene que ser limitada en el tiempo y concretamente definida.

Es bajo esta perspectiva que tenemos que analizar la actividad normativa que ha caracterizado al sistema italiano en tiempos de pandemia.

\section{EL ESTADO DE EMERGENCIA EN ITALIA}

Empezaremos recordando que el sistema italiano, a diferencia de otras experiencias, no prevé una disciplina constitucional para el estado de emergencia ${ }^{7}$. Según lo dicho, el constituyente no quiso dotar al sistema de

nelle limitazioni dei diritti fondamentali si apprezza il bilanciamento tra valori fondamentali: lo Stato costituzionale non può rinunciare mai fino in fondo ai suoi valori costitutivi (costituzionali appunto), anche di fronte al caso imprevedibile e come tale "non previsto, cioè non descritto dall'ordinamento giuridico vigente", cioè, non può contraddire le sue premesse, ma può (e, per continuare a definirsi tale, deve) limitarne l'efficacia nel tempo e nello spazio, e ciò nella misura strettamente necessaria a contenere e risolvere il caso critico".

${ }^{5}$ Cfr. Rolla, 2016: 1999.

${ }^{6}$ Cfr. Silvestri, 2020: "Lo stato di eccezione schmittiano ... presuppone invece uno spazio vuoto, deregolato e riempito dalla volontà del sovrano, inteso come potere pubblico liberato da ogni vincolo giuridico e capace di trasformare istantaneamente la propria forza in diritto".

${ }^{7}$ Puede ser interesante recordar que la doctrina comparte prácticamente de forma unánime la idea que, en estas circunstancias, el denominado "stato di guerra" (art. 78) no puede ser utilizado por analogía, sobre todo por falta de afinidad de la condición actual con una situación conflictual. 
mecanismos que se puedan escapar de las premisas y los límites de legitimidad constitucional y de su control jurisdiccional ${ }^{8}$. De esta forma no serían los fines, sino los medios y las maneras para perseguirlos los considerados extra ordinem ${ }^{9}$.

Sin embargo, esto no quiere decir que la Constitución italiana no haya tomado en consideración la emergencia como posibilidad capaz de atañer al espacio público. Más bien, el constituyente ha querido privilegiar el uso de instrumentos "extraordinarios" dentro del marco ordinario de la vida constitucional del país ${ }^{10}$. Por eso ha dispuesto el procedimiento al que se refiere el artículo $77^{11}$, otorgando al Ejecutivo un espacio de maniobra en casos de urgencia y necesidad $^{12}$.

De esto se desprende que el marco constitucional italiano frente a la covid-19 ha permitido el legítimo desarrollo de una cadena normativa exorbitante (que aquí intentaremos ordenar) que se funda al mismo tiempo sobre actos legislativos o con valor legal y actos normativos del Gobierno, adoptados en conformidad con el principio de legalidad.

Desde la perspectiva legislativa, la base jurídica ha sido representada en principio por la Ley núm. 833 del 23 de Diciembre de 1978, en particular en relación con el artículo 32, en tema de emergencia sanitaria, que otorga poderes relevantes al Ministro de Salud, convirtiéndolo en uno de los protagonistas de esta trama normativa; por otro lado la legitimidad de los actos gubernamentales ha sido garantizada por el Código de protección civil, D.Lgl. núm.1/2018, cuya vigencia (art. 24) ha permitido al Consejo de Ministros

\footnotetext{
${ }^{8}$ Esta perspectiva ha sido tomada desde el principio y guardada por parte de la Corte constitucional.

${ }^{9}$ Cfr. Mortati, 1961: 196.

10 Entre otros: Angiolini, 1988; Modugno, Nocilla, 1988: 513 ss. En los últimos tiempos: Marazzita, 2003; Razzano, 2010.

${ }^{11}$ El artículo77 de la Constitución italiana prevé que: "Il Governo non può, senza delegazione delle Camere emanare decreti che abbiano valore di legge ordinaria.

Quando, in casi straordinari di necessità e di urgenza, il Governo adotta, sotto la sua responsabilità, provvedimenti provvisori con forza di legge, deve il giorno stesso presentarli per la conversione alle Camere che, anche se sciolte, sono appositamente convocate e si riuniscono entro cinque giorni.

I decreti perdono efficacia sin dall'inizio, se non sono convertiti in legge entro sessanta giorni dalla loro pubblicazione. Le Camere possono tuttavia regolare con legge i rapporti giuridici sorti sulla base dei decreti non convertiti".

${ }^{12}$ Véase Cardone, 2011.
} 
declarar el llamado stato di emergenza nazionale, con una duración inicial de seis meses ${ }^{13}$.

Sin embargo, el cuadro de las fuentes normativas primarias ${ }^{14}$ se puede completar solo con referencia a la actividad del Gobierno en el marco del recordado artículo 77 de la Constitución.

En este sentido merece la pena detenernos sobre algunos aspectos que afectan el sistema en su conjunto: efectivamente lo sucedido nos brinda la ocasión de formular reflexiones más amplias sobre los cambios a los que se está sometiendo la forma de gobierno italiana en los últimos años, avanzando por un camino ya emprendido también por otras democracias liberales.

Es indudable que el uso de actos con rango de ley, así como el consecuente sistema de ordenanzas necesarias de urgencia (de las que hablaremos a continuación y cuyo papel se ha ido reforzando semana tras semana) toman su plena legitimidad como imprescindibles medidas de emergencia en primer lugar a partir del contexto internacional (no olvidemos la declaración de emergencia internacional determinada por la WHO) y finalmente habida cuenta de la situación de alto riesgo en la que en pocos días se ha encontrado Italia.

Sin embargo, lo sucedido tal vez nos otorgue la posibilidad de interrogarnos, yendo un poco más allá, no tanto sobre el concepto de necessità e urgenza supuesto por el artículo 77 de la Constitución italiana, sino acerca de la idea de straordinarietà que caracteriza la legislación italiana de urgencia.

Efectivamente, "extraordinarias" no deberían ser solo las circunstancias que califican la situación sino, más bien y sobre todo, el uso mismo de la legislación de urgencia. Por lo tanto: ¿qué opinar en el caso en que el uso de decretos leyes para enfrentarse a un estado de pandemia prolongado se convierta en praxis dejando de ser una excepción? ¿Cuándo una situación por imprevisible que pueda ser (como en el caso de una pandemia) cesa de legitimar el uso de la normativa de urgencia, convirtiéndose en un estado ordinario?

\footnotetext{
${ }^{13}$ Precisamente: "Dichiarazione dello Stato di emergenza in conseguenza del rischio sanitario connesso all'emergenza di patologie derivanti da agenti virali trasmissibili".

${ }^{14}$ Los decretos leyes aprobados durante el lockdown en Italia han sido: d.I. 23 febbraio 2020, n. 6, in G.U. n. 45, 23-2-2020, conv. I. 5 marzo 2020, n. 13, in G.U. n. 61, 9-3-2020; d.I. 25 marzo 2020, n. 19, in G.U. n. 79, 25-3-2020, conv. I. 22 maggio 2020, n. 35, in G.U. n. 132, 23-5-2020. Para trazar un cuadro completo de la actividad normativa del Gobierno italiano para enfrentarse a la pandemia COVID-19 ver: http://www.governo.it/it/approfondimento/coronavirus/13968 .
} 
Dicho de otra forma: ¿seguir tratando todavía la pandemia como una singularidad excepcional que legitima el constante uso de la normativa de urgencia después de más de siete meses desde la declaración de emergencia, así suponiendo que el tiempo "normaliza" la emergencia? ¿O la declaración misma de emergencia legitima el uso de la normativa de urgencia?

La cuestión tiene su relevancia a la hora de comprobar el papel jugado por el poder legislativo en estos meses, en Italia y tal vez en otras democracias liberales.

Por lo que concierne a Italia, hay que subrayar que el sistema político, frente a la concentración del poder en el Ejecutivo (típica en una situación de emergencia y apta a generar cierto desequilibrio entre los poderes) no ha sido capaz de compensar el sistema otorgando el debido protagonismo al Parlamento, que se ha quedado arrinconado ${ }^{15}$.

Semana tras semana, el Legislativo ha quedado parado sin reaccionar, incapaz de ejercer su papel, atrapado en sus debates (alimentados por parte de la doctrina) sobre la posibilidad de reunir las cámaras y votar de forma no presencial $^{16}$. Sin tomar decisiones acerca de las modalidades de trabajo en tiempos de covid-19, el Parlamento italiano se ha limitado a hacer lo estrictamente necesario desde la perspectiva de la legalidad normativa, olvidando su rol de representación, que supone obligaciones de vigilancia y amparo de los derechos y, en particular en tiempos de emergencia, aporta cierto allure democrático a las medidas de urgencia que afectan profundamente las libertades de los ciudadanos, a pesar de su estricta legalidad.

El panorama normativo italiano frente a la covid-19 ha visto crecer día a día el rol del poder ejecutivo que ha encabezado el desarrollo de un régimen basado sobre norme d'ordinanza aprobadas por parte de autoridades administrativas, a nivel tanto nacional como local, cuya legalidad ha sido reafirmada en particular en los decretos leyes núms. 6/2020 y 19/2020, pero cuya autoridad política deja mucho que desear en un contexto de ausencia parlamentaria.

\footnotetext{
${ }^{15}$ Recuerda Clementi, 2020: 44 que si "dal punto di vista formale, è corretto riconoscere che le Camere non hanno mai chiuso davvero i loro battenti, non si può tuttavia non riconoscere che, dal punto di vista sostanziale, vi sia stato durante la prima fase, durata circa un mese, un reale silenzio sulla possibilità di controllare, sindacare, discutere le attività che il Governo stava ponendo in essere in considerazione dell'emergenza".

${ }^{16}$ Tienen gran interés las reflexiones de Curreri, 2020 y Lupo, 2020.
} 


\section{ORDENANZAS NECESARIAS: HABLANDO DE ESTADO REGIONAL}

El uso de ordenanzas necesarias de urgencia es una praxis muy común en el sistema italiano tanto a nivel central como local ${ }^{17}$. A pesar de su más reciente reconocimiento legislativo en actos como las Leyes núms. 14/2017, 113/2018 y la recordada Ley núm. 1/2018, no contamos con una definición compartida, así que podemos coincidir con la última doctrina sobre el tema cuando afirma que tali ordinanze sono provvedimenti autoritativi volti a imporre, vietare e regolare un determinato comportamento, a causa di un evento - più o meno - imprevisto o imprevedibile da contrastare. Provvedimenti giustificati da una necessità, da un'urgenza, il cui contenuto non è prestabilito dalla legge, ma dalla fonte primaria, semplicemente autorizzato e rimesso alla scelta discrezionale dell'organo agente. Un fatto straordinario che, ai sensi di legge, legittima l'ordinanza a regolare il generico ambito di competenza attraverso un particolare potere (extra ordinem), in taluni casi in grado di derogare alla legge stessa, in altri di andare praeter legem o, persino, contra legem. Questo è il tema ricorrente, oggi come ieri, anzi, oggi più di ieri: l'ordinanza, un atto amministrativo (?), una fonte del diritto (?), che può operare addirittura in deroga alla legge (Raffiotta, 2019: 10).

Hay que reconocer que, tras los años, la amplia jurisprudencia constitucional sobre el tema ha contribuido a trazar el perfil de un mecanismo normativo bastante resbaladizo, que hoy se presenta un poco más firme, siendo exigido que cada ordenanza sea motivada, limitada en el tiempo, impugnable y conforme a los principios fundamentales del ordenamiento.

Tal vez el carácter indefinido de estos actos y su uso extenso hayan contribuido a elevar el nivel de confusión normativo que ha ido difundiéndose sobre todo en las primeras semanas tras la declaración del estado de emergencia en Italia. Efectivamente, bajo la legitimación de los decretos leyes, en realidad muy flojos a la hora de definir sus límites, han sido aprobados actos del Ministro de la Salud Pública, actos del Departamento de la Protección Civil, actos regionales

\footnotetext{
${ }^{17}$ Una atenta doctrina ha subrayado como no faltan dudas acerca de su compatibilidad con el marco constitucional: Capellini, A. Cardone, 2016: 399 ss. En clave reconstructiva, cfr. Pinelli, 2009: 317 ss.
} 
y municipales, aunque hay que subrayar que en este panorama, entre tantas ordenanzas de urgencia asumidas, destacan sin duda, tanto bajo el perfil cualitativo como cuantitativo, los decretos del Presidente del Consejo de Ministros, al que el sistema le otorga, en cuanto autoridad nacional de protección civil ${ }^{18}$, un amplio poder de derogación. Lo cual en el caso de la legislación de emergencia covid-19 ha querido decir, también, capacidad de afectar de forma contundente al goce de los derechos constitucionales.

No cabe duda de que el gran número de actos adoptados, junto a sus diferentes rangos, han ido generando una inevitable sensación de desorden entre la ciudadanía. Una sensación no propiamente adecuada en un contexto que, por sí mismo, se presenta como precario y que el derecho debería contribuir a ordenar y ajustar (habida cuenta de que es la plena efectividad de los derechos y su goce integral lo que se está poniendo en juego); una sensación que si bien ha ido menguando con el tiempo, no se ha apagado del todo, a pesar de la aprobación del Decreto Ley núm. 19/2020, que ha intentado una sistematización de lo existente, en particular por lo que concierne a las relaciones entre Gobierno y Parlamento, por un lado, y entre Gobierno y entidades territoriales, por el otro.

Efectivamente, hay que reconocer que si desde la mera perspectiva ciudadanos-Estado pasamos a considerar la dimensión de la gobernanza territorial, la situación parece complicarse: aquí las críticas se hacen patentes y contribuyen a acrecentar esa sensación de desorden de la que hablábamos y que se hace patente por lo que concierne a las relaciones con los poderes territoriales.

Si bien, aunque el citado Decreto Ley núm. 19/2020 ha intentado coordinar la actividad a nivel nacional con aquella local, es evidente que el sistema regional

\footnotetext{
${ }^{18}$ Según el artículo 3.1 a), del Codigo 1/2018, el Presidente del Consejo de Ministros es "autorità nazionale di protezione civile e titolare delle politiche in materia". El Codigo otorga al Presidente también "i poteri di ordinanza in materia di protezione civile", permitiendo que pueda operar "per il tramite del Capo del Dipartimento della protezione civile" (art. 5.1). Sin embargo es el mismo Presidente que "determina le politiche di protezione civile per la promozione e il coordinamento delle attività delle amministrazioni dello Stato, centrali e periferiche, delle regioni, delle città metropolitane, delle province, dei comuni, degli enti pubblici nazionali e territoriali e di ogni altra istituzione e organizzazione pubblica o privata presente sul territorio nazionale" (art. 5.2). El Codigo, además, ordena que el Presidente asuma los actos aptos para definir "gli indirizzi per lo svolgimento, in forma coordinata, delle attività di protezione civile di cui all'articolo 2, al fine di assicurarne l'unitarietà nel rispetto delle peculiarità dei territori' (art. 5.2).
} 
italiano en los últimos meses ha ido manifestando algunas debilidades ${ }^{19}$. Efectivamente, las tensiones que han estado y están estresando el sistema son de tal magnitud que difícilmente podríamos esperar que una simple acción ad hoc de coordinación centro-periferia sería suficiente para sobrepasar esta emergencia. Lo vivido, al contrario, demuestra graves carencias endémicas y que lo que ha hecho y sigue haciendo falta en Italia es un sistema fundado sobre mecanismos firmes de cooperación territorial y sobre el principio de lealtad mutua, que, con el paso del tiempo, se ha convertido en el pilar de todas las organizaciones multinivel mientras en Italia sigue echándose de menos ${ }^{20}$.

Al desconcierto individual y al estado de suspensión social se ha ido sumando un desorden institucional ${ }^{21}$ que ha puesto en evidencia las tensiones que aún permanecen entre el artículo 5 de la Constitución, que habla de la indivisibilidad de la República, y el artículo 2, base del reconocimiento de las formaciones sociales o sea de la dimensión comunitaria como fundamento de la sociedad italiana imaginada en la Constitución ${ }^{22}$. Como si todavía fuera necesario, una vez más se han ido revelando las faltas del sistema regional italiano y la necesidad de poner en marcha un procedimiento que por un lado asegure determinaciones uniformes, y por el otro garantice al mismo tiempo la toma de decisiones con miras a las exigencias locales ${ }^{23}$.

\footnotetext{
${ }^{19}$ A nivel central, con el fin de limitar la actividad normativa local, anteriormente el mismo decreto ley 9/2020 había previsto una cláusula (art. 35) para neutralizar la efectividad de los actos territoriales tomados en contraste con la normativa estatal. El decreto ha sido superado por el d.I. 19/2020 cuyo artículo 2, c. 3, presenta la misma cláusula. Cfr. Morelli, 2020.

${ }^{20}$ En su discurso a la nación, el día 5 de marzo de 2020, el Presidente Mattarella ha recordado que, a pesar de que en condiciones de emergencia le compita al Estado tomar decisiones, hay que subrayar la importancia de la leal colaboración entre los diferentes niveles de gobierno territorial. Cfr. www.quirinale.it/elementi/45537.

${ }^{21}$ Cfr. Clementi, 2020: 41 ss.

${ }^{22}$ Emblemático el caso de la "ordinanza" del día 23 de febrero 2020, adoptada por los alcaldes de Ischia, Casamicciola Terme, Forio, Ischia y Serrara Fontana al fin de prohibir la entrada en el territorio de los respectivos municipios a los turistas procedentes de Lombardia y Veneto, y prontamente anulada por el prefecto de Napoli por razones de desigualdad de trato. De la misma manera llama la atención la "ordinanza contingente e urgente" n. 105 del 5 aprile 2020 adoptada por parte del Alcalde de Messina para limitar el cruce del estrecho entre Calabria y Sicilia solamente a los que se hubiesen previamente registrados on line. La "ordinanza" ha sido anulada por vía extraordinaria (ex artt. 138, t.u. enti locali e 2, comma 3, lett. p), I. n. 400 del 1988) previo dictamen positivo Cons. St., sez. I, 7 aprile 2020, n. 735 - Pres. Torsello, Est. Carpentieri . Véase Ruggeri, 2020: 217 ss. Entrando en la llamada fase 2 merece la pena recordar la decisión n. 841, del 9 de mayo 2020, de la sección I del TAR de la Región Calabria que invalida la ordenanza del Presidente regional con la que se aceleraban los tiempos de reapertura de los establecimientos de restauración: entre otros, Pagano, Saitta, Saitta, 2020: 375 ss.

${ }^{23}$ Cfr. Malo, 2020: 231 ss.
} 
El sistema italiano efectivamente carece de medios capaces de sostener la cooperación centro-periferia más allá de lo que puede asegurar la dinámica intergubernamental de la Conferenza Stato-Regioni, que en estos últimos meses no ha sabido mostrarse a la altura de la situación o, lo que es más probable, no ha podido reivindicar su rol al no tener amparo constitucional, siendo un órgano previsto solo a nivel legislativo.

En primer lugar hay que subrayar que entre marzo y mayo de 2020, o sea durante la temporada del lockdown italiano, la Conferenza Stato Regioni se ha reunido solo dos veces: un número mísero si lo comparamos a la cantidad de actos que han sido aprobados, durante esos mismos meses, por parte del Estado y de las regiones; al nivel de tensión que se ha ido generando entre Estado y regiones en la coordinación de la actividad normativa de ambas y a la frecuencia con la cual la Conferencia suele reunirse en otras temporadas.

En ausencia de otras instituciones, habida cuenta de que estamos hablando de una institución que, a pesar de sus límites estructurales, respecto al sistema en su conjunto ${ }^{24}$ ha sabido dar pruebas de rendimiento, habríamos podido esperar un papel más fuerte jugado por la Conferenza a la hora de buscar la necesaria cooperación entre centro y periferia, tenido en cuenta además del rol que el Código de protección civil asigna a los Presidentes regionales.

Pero la verdad se ha revelado otra.

El Código de 2018 ha sido pensado para enfrentarse a situaciones de emergencia relacionadas a catástrofes naturales y por lo tanto geográficamente más limitadas. El sistema imaginado para armonizar la actividad estatal respecto a aquella de una o algunas regiones se ha demostrado inadecuado a compaginar el activismo normativo de vente gobernadores regionales en constante tensión con la iniciativa del Primer ministro y de los ministros.

En consecuencia el sistema en vez de generar ocasiones de colaboración ha producido dinámicas de competencia, sustentadas por un fuerte espíritu agonístico que no ha facilitado el diálogo favoreciendo la prevalencia de uno u otro sujeto político, pero nunca de un interés común.

Es comprensible y era inevitable que en un primer momento el aparato estatal procediera a ajustes y propusiera modificaciones: el escenario inédito en el que se movía legitimaba cierta actitud indecisa; al mismo tiempo, este espacio

${ }^{24}$ En este sentido, cfr. Mastromarino, 2016. 
resbaladizo, indefinido y totalmente nuevo ha brindado a quien lo precisaba una oportunidad de satisfacer una egoísta necesidad de reafirmar su débil papel institucional $^{25}$ : a veces actuando más allá de lo legalmente posible; en otras ocasiones actuando legítimamente, pero sin contar con la acción de los demás.

Ya era evidente que, a partir de la reforma del sistema regional italiano de 2001, se ha ido manifestando una falta que no puede ser satisfecha de forma diferente que pasando por la reforma del bicameralismo y dotando al Parlamento italiano de una Cámara de representación territorial ${ }^{26}$, a fin de involucrar a las regiones en el proceso decisional político, responsabilizando su papel institucional, sin conformarse con su participación a nivel ejecutivo a través del funcionamiento de las relaciones intergubernamentales en fase de actuación.

Como era de esperar, esta falta se ha hecho más patente en un grave momento de crisis como el que hemos vivido y todavía vivimos y se ha ido sumando, en la opinión de quien escribe, al escaso uso de medios, no obstante presentes en la Constitución italiana, que podrían simplificar las relaciones centro-periferia en casos de emergencia, pero que, sobre todo por falta de cultura de la descentralización, o nunca han sido actuados o han sido interpretados de forma muy limitada, sin poder expresar todas sus potencialidades.

Por ejemplo, entre los artículos constitucionales que en estas circunstancias hubiesen merecido un uso más atrevido hay que recordar, sin duda, el artículo 120.2, realmente muy poco explotado ${ }^{27}$.

En particular no parece arriesgado haber imaginado un uso del artículo 120.2 no solo en caso de incumplimiento regional, según la común interpretación, sino también en caso de emergencia o frente a una coyuntura independiente de la acción o inacción de la región, habida cuenta de que la Corte constitucional (averiguados los supuestos principios de proporcionalidad, leal colaboración y

\footnotetext{
${ }^{25}$ Cfr. Cortese, 2020: 3 ss.

${ }^{26}$ Cfr. Mastromarino, 2017: 32 ss.

${ }^{27}$ El artículo 120 al II y III parrafo prevé que: "Il Governo può sostituirsi a organi delle Regioni, delle Città metropolitane, delle Province e dei Comuni nel caso di mancato rispetto di norme e trattati internazionali o della normativa comunitaria oppure di pericolo grave per l'incolumità e la sicurezza pubblica, ovvero quando lo richiedono la tutela dell'unità giuridica o dell'unità economica e in particolare la tutela dei livelli essenziali delle prestazioni concernenti i diritti civili e sociali, prescindendo dai confini territoriali dei governi locali. La legge definisce le procedure atte a garantire che i poteri sostitutivi siano esercitati nel rispetto del principio di sussidiarietà e del principio di leale collaborazione".
} 
suficiencia) siempre se ha mostrado tolerante respecto a una interpretación amplia del artículo ${ }^{28}$.

El hecho de que la literalidad del artículo 120.2 no haga ninguna referencia a la inercia regional o a la falta de respuesta por parte de la región, efectivamente permite hipotetizar que la intervención del Estado puede darse tanto en sentido correctivo, en caso de pasividad de la región, come en caso de emergencia y por lo tanto de urgencia frente a un pericolo grave per l'incolumità e la sicurezza pubblica, ovvero quando lo richiedono la tutela dell'unità giuridica o dell'unità economica e in particolare la tutela dei livelli essenziali delle prestazioni concernenti $i$ diritti civili e sociali, como reza el artículo. La norma, en coherencia con principios como el de autonomía y soberanía, por lo tanto, quedaría abierta a casos en los cuales la inercia regional sea debida a razones, por decirlo así, objetivas e independientes de la voluntad regional ${ }^{29}$.

La sustitución de la región por parte del Estado, por lo tanto, podría ser generada por razones diferentes entre las cuales, junto a circunstancias patológicas del sistema (como la inactividad regional), encontramos situaciones de emergencia capaces de poner en riesgo al sistema en su conjunto ${ }^{30} \ldots$ como, evidentemente, en el caso de la pandemia covid-19.

Quedo convencida que el uso del artículo 120.2 de la Constitución estaba entre las posibilidades que tenía el gobierno en estas circunstancias, y hubiese ahorrado (sobre todo explotando las posibilidades ofrecidas por un espacio de cooperación como la Conferenza Stato-Regioni), tanto desorden normativo a la hora de coordinar el papel estatal con el rol regional en la gestión del estado de emergencia presente.

\footnotetext{
${ }^{28}$ En particular, después de la reforma de 2001, merece la pena recordar la decisión núm. $6 / 2004$, donde la Corte reafirma su favor hacia el reconocimiento de la posibilidad de una sustitución "previa" a cualquiera inactividad por parte de la región frente a una situación de necesidad.

${ }^{29}$ Podríamos así probar a distinguir entre "emergencia/urgencia" por un lado y "necesaria intervención" por el otro.

${ }^{30}$ Véase De Michele, 2008: 678; Gianfrancesco, 2001: 185. Levanta algunas dudas Mainardis, 2001: 1398.
} 


\section{MIRANDO HACIA EL FUTURO. EL VALOR DE LAS INQUIETUDES DEL JURISTA}

A pesar de tanto desbarajuste a nivel normativo (evidentemente, sobre todo en las primeras semanas sucesivas a la declaración del estado de emergencia) hay que reconocer que la sociedad civil italiana ha cumplido generalmente con todas las instrucciones, reaccionando bien y de forma civilizada a las necesidades.

Pero quizás tendremos que asumir la idea de que lo extraordinario se pueda convertir en algo ordinario, tomando en cuenta la posibilidad de que lo que está ocurriendo necesite tiempo para pasar. Tal vez por eso las inquietudes que han manifestado los juristas en estos meses terminen por jugar un rol importante, porque les permiten convertirse en atentos guardianes del Estado de Derecho, sobre todo pro futuro.

Realmente estoy convencida de que el verdadero desafío en términos de democracia y protección de derechos será lanzado mañana, cuando la situación se vaya apaciguando.

Será mañana, efectivamente, cuando podamos averiguar las consecuencias que se habrán desprendido a partir de esta indigestión de poder ejecutivo y los cambios que se habrán producido. Mañana podremos medir la solidez de nuestros sistemas democráticos, en función de si serán capaces de dar pasos atrás después de tantos pasos adelante con deterioro de la libertad de los ciudadanos.

Hay que vigilar que el estado de necesidad se agote al cesar la emergencia, llevándose consigo todo su aparato normativo de urgencia, sin resacas de autoritarismo, sin extender más las restricciones de la libertad de los ciudadanos.

El jurista está llamado hoy a prestar atención a algunas inquietudes que van surgiendo, pero más aún está llamado mañana a velar para que esas inquietudes no encuentren terreno fértil para echar raíces.

Lo que hoy parece necesario, mañana tiene que volver a ser superfluo. El peligro es que, aprovechando los tiempos difíciles que estamos viviendo, nos caiga encima una temporada en la que las conocidas democracias iliberales ya no nos parezcan tan indecentes, sino más bien indispensables para nuestra 
seguridad; una temporada en la que el miedo nos haga sacrificar nuestro patrimonio de derechos a cambio de unas supuestas tranquilidad y garantía.

Allí tendrá que estar el jurista, defensor de la Constitución, de sus mecanismos, de sus garantías, de sus derechos.

Sin duda la crisis que estamos viviendo ha estresado el sistema desde el punto de vista de las garantías de los derechos fundamentales. La emergencia ha empujado hacia unos límites extremos el Estado de derecho. Lo cual es comprensible si consideramos las circunstancias excepcionales a las cuales hemos tenido que enfrentarnos (y todavía nos enfrentamos). Hemos asistido a un trastorno del sistema de fuentes, cuya legitimidad hemos intentado asegurar a través de la continua referencia al principio de legalidad, en algunos casos reducido a un imperceptible hilo capaz de validar la acción del ejecutivo, que ha comprimido profundamente el goce de las libertades constitucionales. Hemos aceptado que la mayoría de los derechos fundamentales pudieran ser aplastados, casi neutralizados, pero solo en virtud de una ponderación en favor del derecho a la vida. Hemos renunciado temporalmente a nuestras prerrogativas políticas, pero solo en nombre de una responsabilidad que como miembros de una comunidad nos empuja a ser sensatos.

Sin embargo, hay que subrayar que ahora que han pasado varios meses desde la declaración de emergencia, si bien el peligro no se ha reducido y la pandemia está contenida, pero no vencida, queda un espacio para reflexionar y dejar que esas inquietudes se concreten en consideraciones acerca de algunos pilares del Estado de Derecho, que una vez más pueden asegurarnos sobre el buen estado de salud de nuestro sistema... a pesar de todo.

Hablo en primer lugar del control jurisdiccional de los actos adoptados (especialmente por lo que concierne a la justicia administrativa ${ }^{31}$ ), que no cesa de ser activo a pesar de las dificultades del momento y, aunque demorándose un poco más, no deja de asegurar la conformidad constitucional de la acción política, sobre todo cuando afecta las libertades de los ciudadanos.

Además, garantiza que los límites que se imponen a los derechos fundamentales sean fruto de un balance y no consecuencia de su suspensión. $\mathrm{Si}$, como se recordará, la suspensión de los derechos no tiene cabida en el

31 ... Habida cuenta de que los decretos del Presidente del Consejo de Ministros son actos del ejecutivo que no pueden ser impugnados frente a la Corte constitucional italiana al no tener rango legal. 
sistema constitucional italiano, teniendo en cuenta que no se prevé la posibilidad de declarar un estado de excepción, debemos concluir que la limitación de los derechos no afecta a su titularidad sino a la intensidad de su goce, que puede verse restringido, a lo mejor, pero solo a causa del balance entre las diferentes libertades en juego.

En este sentido hay que aclarar que la Constitución italiana no dispone de ningún tipo de jerarquía entre los derechos, inclinándose por un sistema integrado que prefiere la técnica de la ponderación concreta, en vez de una clasificación de derechos. Sin embargo, no se puede obviar que en Italia la fuerza del contagio ha sido lo suficientemente elevada como para obligar al legislador a tomar unas decisiones drásticas que, favoreciendo el derecho a la salud $^{32}$, han restringido profundamente otras libertades fundamentales, como la de circulación, de reunión, de culto, de privacidad, inviolabilidad del domicilio... Efectivamente, más de 30.000 víctimas terminan por casi neutralizar cualquier hipótesis de ponderación, estando en juego el bien fundamental de la vida.

Sin embargo, otra vez nos encontramos frente a la necesidad de diferenciar el hoy respecto del ayer: razonar en términos de ponderación y no de suspensión, efectivamente nos obliga a sopesar las circunstancias del contexto a fin de no reducir unos derechos en favor de otros sin justificar las restricciones ${ }^{33}$.

Le corresponde al juez determinar que la ponderación es llevada a cabo correctamente, habida cuenta, día a día, de las circunstancias concretas, a fin de no reducir más de lo debido el ámbito de fricción de las libertades constitucionales. Es evidente que a pesar del riesgo para la salud por el que estamos pasando queda espacio para averiguar que las restricciones sean ponderadas y no injustificadas, como en el caso del derecho a la privacidad de los datos; así como sigan siendo garantizados aquellos derechos que no se ven afectados de la situación, como el derecho a ser informados por ejemplo, de forma plena y verdadera.

Igualmente queda en manos del sistema jurisdiccional acertar que el nivel de calidad de los derechos siga siendo aquello que se pretende en un Estado que, como la Constitución italiana establece, pone en el centro de su actividad a la dignidad humana. Lo cual nos lleva a no bajar la guardia en particular respecto al nivel de protección de aquellos derechos que no conciernen directamente a

32 ...reconociendo además su relevancia colectiva: entre otros véase B. Caravita, L'Italia ai tempi del coronavirus: rileggendo la Costituzione italiana, en Federalismi.it, núm. 6/2020.

${ }^{33}$ Cfr. Algostino, 2020: 116 ss. 
la salud pero permiten al individuo vivir la enfermedad y la terapia en conformidad a su identidad cultural o religiosa; o aseguran que en un momento tan difícil como el que estamos viviendo, no se vea impedida la solidaridad, que nos pide el modelo de constitucionalismo democrático al que estamos adheridos, hacia los que se encuentran desprotegidos socialmente y económicamente, deshumanizándolos.

Las condiciones de descuido en las que, en Italia, han caído las cárceles, los asilos de ancianos y los centros de migrantes en las semanas de lockdown demuestran una vez más cómo los grupos vulnerables están condenados a vivir una emergencia en la emergencia, viendo empeorarse su condición de postergados entre los postergados ${ }^{34}$.

Como suele pasar en los momentos críticos, en los meses pasados la situación ha puesto en evidencia la resiliencia de mi país y su capacidad de enfrentarse, sin tener referencias, a una situación totalmente nueva. Pero también se han puesto en evidencia los límites del sistema: límites que conciernen en primer lugar a las dificultades que, desde hace varios años, encuentra el Parlamento para encontrar su papel en una dinámica política cada día más centrada sobre efímeros protagonistas, más bien que fundada sobre ideas y proyectos a largo plazo ${ }^{35}$. No es una casualidad si, en estos días, ámbitos como el del bienestar, la salud pública y la educación se encuentran, más que otros, desamparados frente a la emergencia: han estado sufriendo, por años, recortes financieros, disminución de personal, descuido en términos de planificación. Sin hablar de la competencia con el sector privado, apoyado por el mismo Estado.

Y mucho también queda por decir acerca de la organización territorial del Estado cuya disfunción termina inevitablemente por afectar al pleno goce de los derechos. Su perfil, con el tiempo y debido a reformas del sistema que yo definiría como "inacabadas", se ha ido deformando sin que nuevos contornos hayan ido asomándose, propiciando adaptaciones precarias que se han

\footnotetext{
${ }^{34}$ Sobre las condiciones de los centros penitenciarios, Lorenzetti, 2020: 48 ss.; en tema de protección de migrantes véase el documento Emergenza Covid-19. L'impatto sui diritti delle/dei cittadine/i straniere/i e le misure di tutela necessarie: una prima ricognizione, 22 marzo 2020. A lo dicho se suma la condición de las mujeres en tiempo de pandemia: Ronchetti, 2020; Filice, 2020.

${ }^{35}$ Massa Pinto, 2020, subraya el estado de "eclissi della politica, in un circolo vizioso senza fine nel quale tale eclissi costituisce al medesimo tempo la causa e l'effetto del fenomeno: lo stato comatoso nel quale si trova la politica alimenta le tendenze segnalate e a loro volta queste tendenze mortificano ulteriormente la politica".
} 
demostrado poco eficaces frente a la necesidad de actuar con urgencia y firmeza.

Lo que estamos viviendo nos desafía para el futuro: cada crisis supone un cambio. Depende de nosotros elegir la naturaleza y la dirección de los cambios que queremos introducir. Puede que la emergencia que estamos viviendo se convierta en una ocasión para enderezar el curso del Estado de Derecho, fortaleciendo esos puntos débiles del sistema que ya hace tiempo se están manifestando. $\mathrm{O}$ al contrario, pues puede que la pandemia dé un duro golpe a los pilares de la democracia liberal. Nada está decidido, todo queda en nuestras manos. En las manos de los juristas sobre todo.

Pero permítanme una última reflexión.

Espero que la idea del cambio como condición inevitable frente a la crisis sea asumida por parte de la Unión Europea también: no puedo concluir estas breves notas sin una referencia a Europa, deseando que despierte de su largo sueño, antes de que ese sueño se convirtiera en una pesadilla. Me parece que hay señales en esa dirección.

Es tiempo para la Unión de cambiar el paso. Y tiene que hacerlo ahora, abriendo un nuevo proceso constituyente. Ya no queda espacio para los nacionalismos, sea cual sea su naturaleza. La temporada del Estado-nación se ha acabado hace tiempo: vivimos en una época en la que o nos salvamos todos o nadie se salva. En Europa o hay integración política, del sistema de derechos, del welfare, sustentado por un sistema fiscal común o ya no tiene sentido ningún proyecto económico y comercial a nivel regional.

La pandemia nos lo está demostrando de forma contundente.

\section{BIBLIOGRAFIA}

- AlGOStinO, A., "Covid-19: primo tracciato per una riflessione nel nome della Costituzione", Osservatorio AIC, núm. 3, 2020.

- ANGIOLINI, V., Necessità ed emergenza nel diritto pubblico, Cedam, Padova, 1986. 
- CAPELLINI, P., CARDONE A. "Le sorti dell'eccezione nell'esperienza costituzionale italiana. Stato democratico pluralista e poter extra ordinem", Scritti in onore di Gaetano Silvestri, Vol. I, Giappichelli, Torino, 2016.

- CARAVITA, B., "L'Italia ai tempi del coronavirus: rileggendo la Costituzione italiana”, Federalismi.it, núm.6, 2020.

- CARDONE, A., La «normalizzazione» dell'emergenza. Contributo allo studio del potere extra ordinem del Governo, Giappichelli, Torino, 2011.

- CLEMENTI, F., "Il lascito della gestione normativa dell'emergenza: tre riforme ormai ineludibili", Osservatorio AIC, núm.3, 2020.

- CORTESE, F., "Stato e Regioni alla prova del coronavirus", le Regioni, núm. $1,2020$.

- CURRERI, S. "Il Parlamento nell'emergenza", Osservatorio AIC, núm.3, 2020.

- DE MICHELE, A., "L'art.. 120 della Costituzione e il suo ruolo nella riforma del Titolo V", Le Istiruzioni del Federalismo, núm. 5, 2008.

- FILICE, F., "La parità di genere alla prova del Covid 19", Diritto Penale e Uomo, núm. 4, 2020.

- GIANFRANCESCO, E., "Il potere sostitutivo", T. Groppi, M. Olivetti, La Repubblica delle autonomie, Giappichelli, Torino, 2001.

- LORENZETTI, A., "Il carcere ai tempi dell'emergenza Covid-19", Osservatorio costituzionale, núm. 3, 2020.

- LUCIANI, M. "Il sistema delle fonti di diritto alla prova dell'emergenza", Rivista dell'Associazione italiana dei costituzionalisti, núm.2, 2020.

- LUPO N., "Perché non è l'art. 64 Cost. a impedire il voto "a distanza" dei parlamentari. E perché ammettere tale voto richiede una "re-ingegnerizzazione" dei procedimenti parlamentari”, Osservatorio AIC, núm.3, 2020.

- MAINARDIS, C. "I poteri sostitutivi statali: una riforma costituzionale con (poche) luci e (molte) ombre", le Regioni, núm. 6, 2001.

- MALO, M. "Le Regioni e la pandemia. Variazioni sul tema", le Regioni, núm.2, 2020. 
- MARAZZITA, G. L'emergenza costituzionale. Definizioni e modelli, Giuffrè, Milano, 2003.

- MASSA PINTO, I. "La tremendissima lezione del Covid-19 (anche ai giuristi)", Questione e Giustizia, 18 de marzo 2020.

- MASTROMARINO, A. "Audizione del 9 giugno 2016 alla Commissione parlamentare per le questioni regionali nell'ambito dell'indagine conoscitiva sulle forme di raccordo tra lo Stato e le autonomie territoriali, con particolare riguardo al "sistema delle conferenze", Osservatorio AIC, núm.2, 2016.

- "El sistema regional italiano: comenzar por el Senado", Cuadernos Manuel Giménez Abad, núm.14, 2017.

- MODUGNO, F., Nocilla D., "Problemi vecchi e nuovi sugli stati di emergenza nell'ordinamento italiano", Scritti in onore di Massimo Severo Giannini, vol. III, Giuffré, Milano, 1988.

- MORELLI, A. "Il Re del piccolo principe ai tempi del coronavirus. Qualche riflessione su ordine istituzionale e principio di ragionevolezza nello stato di emergenza", Diritti regionali. Rivista di diritto delle autonomie territoriali, núm.1, 2020.

- MORTATI C. "Costituzione (dottrine generali)", Enc. Dir., XI, Giuffrè, Milano, 1961.

- PAGANO F.F., SAITTA A., SAITTA F. "Il giudice amministrativo stoppa la ripartenza anticipata della Regione Calabria: sul lockdown è lo Stato a dettare legge", Osservatorio AIC, núm.3, 2020.

- PINELLI, C. "Un sistema parallelo. Decreti-legge e ordinanze d'urgenza nell'esperienza italiana", Diritto pubblico, núm.2, 2009.

- PINNA, P. L'emergenza nell'ordinamento costituzionale italiano, Giuffrè, Milano, 1988.

- RAFFIOTTA E.C. Norme d'ordinanza. Contributo a una teoria delle ordinanze emergenziali come fonti normative, Bonomia University Press, Bologna, 2019.

- RAVÍ PINTO, R. "Brevi considerazioni su Stato d'emergenza e Stato costituzionale”, Biolaw Journal, Special Issue, núm.1, 2020. 
- RAZZANO, G. L'amministrazione dell'emergenza. Profili costituzionali, Cacucci, Bari, 2010.

- ROLLA, G. "Profili costituzionali dell'emergenza", Scritti in onore di Gaetano Silvestri, Vol. III, Giappichelli, Torino, 2016.

- RONCHETTI, L. "La pandemia costituzionale in un'ottica di genere", European Law and Gender, 30 de marzo 2020.

- RUGGERI, A. "Non persuasivo il parere reso, dietro sollecitazione del Governo, dal Consiglio di Stato su un'ordinanza del Sindaco De Luca relativa all'attraversamento dello Stretto di Messina", Consulta OnLine, 2020.

- SÁNCHEZ FERRIZ, R. "Estado de alarma y defensa de la Constitución", Levante, 5 de avril 2020.

- "Reflexiones constitucionales desde el confinamiento", Actualidad Jurídica Iberoamericana, 2020.

— SILVESTRI, G. "Covid-19 e Costituzione", www.unicost.eu, 10 de Avril 2020.

- VEDASCHI, A. "Il Covid-19, l'ultimo stress test per gli ordinamenti democratici: uno sguardo comparato", DPCE on line, núm. 2, 2020. 